\title{
$A B O$ groups can play a role in susceptibility and severity of COVID-19
}

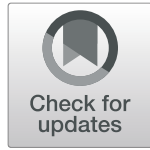

S. Samra" ${ }^{*}$, M. Habeb ${ }^{1,2}$ and R. Nafae ${ }^{1}$

\begin{abstract}
Background: A few people infected by the coronavirus become seriously ill, while others show little to no signs of the symptoms, or are asymptomatic. Recent researches are pointing to the fact that the ABO blood group might play an important role in a person's susceptibility and severity of COVID-19 infection. Aim of the study: try to understand the relationship between ABO groups and COVID-19 (susceptibility and severity).

Results: A total of (507) patients were included in this study. The study population was divided based on the $A B O$ blood group into types $\mathrm{A}+, \mathrm{A}-, \mathrm{B}+, \mathrm{AB}, \mathrm{O}+$, and $\mathrm{O}-$. Blood group $\mathrm{A}$ was associated with high susceptibility of infection: group A, 381 (75.1\%); and less common in group O, 97 (19.2\%), group B, 18 (3.5\%), and group AB, 11 (2.2\%). The severity of COVID-19 infection was common in non-blood group $O$ where $(20(7.1 \%), 4$ (26.7\%), 2 (11\%), and $1(9 \%)$ in type $A+, A-, B+$, and $A B$, respectively), while in type $O 3.1 \%$. And mechanically ventilated patients were $22(5.9 \%), 2(13.4 \%), 2$ (11.1\%), and 1 (1\%). Mortality was high in blood groups A and B, $16(4.37 \%)$ and 1 $(5.5 \%)$, respectively, while in blood group $\mathrm{O}$, it was $1 \%$.

Conclusion: The incidence, severity, and mortality of COVID-19 were common in non-blood group O. While blood group O was protected against COVID-19.
\end{abstract}

Keywords: COVID-19, ABO blood groups, Severity, Mortality

\section{Background}

The rapid global spread of the novel coronavirus SARSCoV-2 has strained existing healthcare and testing resources, and it is causing COVID-19 to hit some people harder than others, with some people experiencing only mild symptoms and others being hospitalized and requiring ventilation. Making the identification and prioritization of individuals most at risk a critical challenge.

The pathogenesis of severe COVID-19 and the associated respiratory failure are still unclear, but the higher mortality is consistently tied to older age and being male. Further, people with underlying health conditions are more likely to develop severe COVID-19, including hypertension, diabetes, being obese, and cardiovascular disease [1]. Biological factors that determine susceptibility to

\footnotetext{
*Correspondence: saad_samara2003@yahoo.com

'Zagazig University, Zagazig, Egypt

Full list of author information is available at the end of the article
}

SARS-CoV-2 and severity of COVID-19 are yet to be fully understood. Many studies have implicated that the ABO blood type is a potential risk for various diseases such as cancer, myocardial infarction, acute kidney injury, and venous thromboembolism [2,3]. The ABO blood grouping may influence the susceptibility of COVID-19 and the severity of the disease [4]. The aim of the study is to study if there is a relationship between the $\mathrm{ABO}$ groups and COVID-19 (susceptibility and severity).

\section{Methods \\ The study was conducted on 507 COVID-19-confirmed patients admitted in the King Fahd Hospital Almadina Almonoura, KSA, and approved with ethics approval and consent to participate of King Fahd Hospital- Medina, KSA. The written consent from the patients was taken; 401 patients (79\%) were admitted in isolation wards while 106 patients (21\%) in the ICU, with a mean age \pm SD of $54.6 \pm 9$ with a male to female ratio of 303}


(59.7\%) and 204 (40.3\%), respectively, from the 15 April 2020 to 30 July 2020.

All patients underwent the following:

1. Through medical history: especially smoking history and any comorbid condition such as hypertension and diabetes mellitus.

2. The diagnosis of COVID-19 was confirmed by a positive real-time reverse transcriptase polymerase chain reaction test of SARS-CoV-2 on nasal and pharyngeal swab specimens from patients.

3. ABO grouping is done through blood grouping reagent anti-monoclonal diagnostic test kit. Mediclone Biotech Private Limited, India.

4. Determine the severity of COVID-19 infection. According to ACEP2020 [5] divided patient condition into the following:
(a) Mild low risk
(b) Mild at risk
(c) Moderate
(d) Severe
(e) Critical

5. Follow up the patients to know the prognosis of the disease cured or died (from 14 to 39 days).

Inclusion criteria:

- Any COVID-19 patient agrees to participate in the study

Exclusion criteria:

- The age of COVID-19 patient is less than 18 years.

Table 1 Some epidemiological and clinical parameters among the $A B O$ group

\begin{tabular}{|c|c|c|c|c|c|c|}
\hline & $A+(366)$ & $A-(15)$ & $\mathrm{B}+(18)$ & $A B+(11)$ & $0+(94)$ & \\
\hline Age & $54.5 \pm 11$ & $51.9 \pm 4$ & $52.1 \pm 6$ & $52 \pm 9$ & $54.7 \pm 8$ & $53.2 \pm 7$ \\
\hline \multicolumn{7}{|l|}{ Sex } \\
\hline Male & 212 & 9 & 11 & 6 & 63 & 2 \\
\hline Female & 154 & 6 & 7 & 5 & 31 & 1 \\
\hline BMI & $25 \pm 4$ & $24.5 \pm 5$ & $24 \pm 3$ & $23 \pm 7$ & $24.1 \pm 5$ & $24.4 \pm 6$ \\
\hline \multicolumn{7}{|l|}{ Smoking history } \\
\hline Non & 87 (23.7\%) & $4(26.7 \%)$ & 7 (38.9\%) & $4(36.3 \%)$ & $24(25.5 \%)$ & $1(33.4 \%)$ \\
\hline Mild & 128 (34.9\%) & $5(33.3 \%)$ & $4(22.3 \%)$ & $3(27.2 \%)$ & $33(35.1 \%)$ & $1(33.4 \%)$ \\
\hline Moderate & 90 (24.5\%) & $3(20 \%)$ & $4(22.3 \%)$ & $3(27.2 \%)$ & 21 (22.3\%) & $1(33.3 \%)$ \\
\hline Heavy & $61(16.7 \%)$ & $3(20 \%)$ & $3(16.7 \%)$ & $1(9.3 \%)$ & $16(17.1 \%)$ & - \\
\hline \multicolumn{7}{|l|}{ Comorbidity } \\
\hline No comorbidity & 57 (15.5\%) & $3(20 \%)$ & $3(16.7 \%)$ & $4(36.3 \%)$ & $41(43.6 \%)$ & $1(33.3 \%)$ \\
\hline HTN & 202 (55.2\%) & 8 (53.4\%) & $6(33.4 \%)$ & 8 (72.7\%) & $20(21.2 \%)$ & - \\
\hline DM & 198 (54\%) & $6(40 \%)$ & $5(27.8 \%)$ & $8(72.7 \%)$ & $22(32.4 \%)$ & $2(66.7 \%)$ \\
\hline IHD & 119 (32.5\%) & $3(20 \%)$ & $2(11 \%)$ & $2(18.1 \%)$ & 15 (15.9\%) & - \\
\hline CVA & 177 (48.3\%) & $2(13.4 \%)$ & $2(11 \%)$ & $4(36.2 \%)$ & $7(7.4 \%)$ & - \\
\hline Chronic chest disease & $25(6.8 \%)$ & $1(6.7 \%)$ & - & $1(9 \%)$ & $12(12.7 \%)$ & - \\
\hline Bronchial asthma & $17(68 \%)$ & $1(100 \%)$ & - & - & $8(66.7)$ & - \\
\hline Bronchiectasis & $8(32 \%)$ & - & - & $1(100 \%)$ & $4(33.3 \%)$ & - \\
\hline \multicolumn{7}{|l|}{ Severity of COVID-19 } \\
\hline Mild low risk & $280(76.5 \%)$ & $6(40 \%)$ & $9(50 \%)$ & $3(27.2 \%)$ & $51(54.2 \%)$ & $2(66.7 \%)$ \\
\hline Mild at risk & $18(4.9 \%)$ & $1(6.7 \%)$ & $2(11.1 \%)$ & $3(27.2 \%)$ & $23(24.4 \%)$ & - \\
\hline Moderate & $30(8.1 \%)$ & $1(6.7 \%)$ & $3(16.7 \%)$ & $3(27.2 \%)$ & $10(10.6 \%)$ & $1(33.3 \%)$ \\
\hline Severe & $12(3.2 \%)$ & $3(20 \%)$ & $1(5.5 \%)$ & $1(9 \%)$ & $5(5.3 \%)$ & - \\
\hline Critical & $26(7.1 \%)$ & $4(26.7 \%)$ & $2(11.1 \%)$ & $1(9 \%)$ & $3(3.1 \%)$ & - \\
\hline MV & 22 (5.9\%) & 2 (13.4\%) & 2 (11.1\%) & 1 (9\%) & 1 (1\%) & - \\
\hline \multicolumn{7}{|l|}{ Outcome } \\
\hline Died & 16 (4.37\%) & - & $1(5.5 \%)$ & - & $1(1 \%)$ & - \\
\hline
\end{tabular}




\section{Statistical analysis}

An analysis, using SPSS version 12, was performed with respect to the main study aim. Descriptive characteristics for participants are expressed as means and standard deviation (SD) for continuous variables, and number and percentage for categorical variables. We used the independent sample test to show the significant difference between the continuous variable and the chi-square test for the categorical variables. The level of significance was accepted at $p \leq 0.05$.

\section{Results}

In Table 1, COVID-19 was common in males than in females (303 (59.7\%) and 204 (40.2\%), respectively). Most of the COVID-19 patients were mild to moderate smoker while heavy and nonsmoker was less common (58.4\%, 16.5\%, 25\%). HTN, DM, IHD, and CVA were the most common comorbid among COVID-19 patients (48.1\%, $47.5 \%, 27.8 \%, 37.8 \%$, respectively) while chronic chest diseases (bronchial asthma, bronchiectasis) were less common $(5.1 \%, 2.5 \%$, respectively). Most of the COVID-19 patients were mild to moderate cases (449 patients $(88.6 \%))$, while critical patients were $36(7.1 \%)$, mechanically ventilated patients were 28 patients $(5.5 \%)$, and about $4 \%$ of the patients died, mostly patients who were in blood group A 16/18 patients (88.9\%).

In Table 2, there were no significant differences between blood group $\mathrm{A}$ and blood group $\mathrm{O}$ regarding the age of the patients, male/female, and BMI of the patients $[(54.3 \pm 9,55.3 \pm 7),(58 / 42 \%, 67 / 33 \%),(24.7 \pm 6,24.9 \pm$ $8)$, respectively]. There was no significant difference between the two groups regarding smoking index (mild, moderate, and heavy: $34.9 / 35 \%, 24.4 / 22.6 \%, 16.8 / 16.5 \%$, respectively) while there was a significant increase in

Table 2 Comparison between blood group A and blood group O regarding epidemiological characters of COVId19 patients

\begin{tabular}{|c|c|c|c|c|}
\hline & Blood group $(A)(381)$ & Blood group $(0)(97)$ & Test of sig $\mathrm{T}$ & $P$ value \\
\hline $\begin{array}{l}\text { Age (years) } \\
\text { Mean } \pm \text { SD }\end{array}$ & $54.3 \pm 9$ & $55.3 \pm 7$ & 0.89 & 0.154 \\
\hline \multirow[t]{2}{*}{ BMI (Mean \pm SD) } & $24.7 \pm 6$ & $24.9 \pm 8$ & 0.9 & 0.12 \\
\hline & $\mathrm{NO} / \%$ & No $/ \%$ & $x^{2}$ & $P$ value \\
\hline Male & $221(58 \%)$ & $65(67 \%)$ & 1.4 & 0.21 \\
\hline Female & $160(42 \%)$ & • 32(33\%) & 0.19 & 0.14 \\
\hline \multicolumn{5}{|l|}{ Smoking History: } \\
\hline Non & $91(23.8 \%)$ & $25(25.7 \%)$ & 1.24 & 2.14 \\
\hline Mild & $\cdot 133(34.9 \%)$ & $34(35 \%)$ & 2.01 & 1.25 \\
\hline Moderate & $93(24.4 \%)$ & $22(22.6 \%)$ & 0.35 & 1.58 \\
\hline Heavy & $64(16.8 \%)$ & $16(16.5 \%)$ & 1.02 & 0.687 \\
\hline \multicolumn{5}{|l|}{ Comorbidity } \\
\hline No comorbid & $60(15.7 \%)$ & $42(43.2 \%)$ & 0.357 & 0.241 \\
\hline HTN & $210(55.1 \%)$ & $20(20.6 \%)$ & 4.5 & $0.001^{* *}$ \\
\hline DM & $204(53.5 \%)$ & $24(24.7 \%)$ & 9.7 & $0.00^{* *}$ \\
\hline $\mathrm{IHD}$ & $122(32 \%)$ & $15(15.5 \%)$ & 5.3 & $0.001^{* *}$ \\
\hline CVA & $179(46.98 \%)$ & $7(7.2 \%)$ & 11.4 & $0.001^{* *}$ \\
\hline Chronic Chest dis & $26(6.8 \%)$ & $12(12.3 \%)$ & 8.7 & $0.00^{* *}$ \\
\hline Br. asthma. & 18(69.2\%) & $8(66.7 \%)$ & 4.5 & \\
\hline Bronchiectasis & $8(30.8 \%)$ & $4(33.35)$ & 3.8 & \\
\hline \multicolumn{5}{|l|}{ Severity of COVID19 } \\
\hline Mild low risk & $283(75 \%)$ & $53(54.6 \%)$ & 1.75 & 0.025 \\
\hline Mild at risk & 19(4.9\%) & $23(23.7 \%)$ & 0.214 & 0.021 \\
\hline Moderate & $31(8.1 \%)$ & $11(11.3 \%)$ & 2.86 & $0.001^{* *}$ \\
\hline Severe & 15(3.9\%) & $5(5.1 \%)$ & 2.98 & $0.001^{* *}$ \\
\hline Critical & $30(7.8 \%)$ & $3(3 \%)$ & 3.24 & $0.001^{* *}$ \\
\hline MV & $24(6.2 \%)$ & $2(2 \%)$ & 4.12 & $0.001^{* *}$ \\
\hline Died & $16(4.1 \%)$ & $1(1 \%)$ & 3.4 & $0.01^{* *}$ \\
\hline
\end{tabular}

HTN hypertension, DM diabetes mellitus, IHD ischemic heart diseases, CVA cerebro-vascular stroke, MV mechanical ventilation

${ }^{* *}$ :has significant level 
comorbid condition HTN, DM, IHD, CVA, and chronic chest diseases such as bronchial asthma and bronchiectasis $[(55.1 \%, 20.6 \%),(53.5 \%, 24.7 \%),(32 \%, 15.5 \%)$ and (46.9\%, 7.2\%) (26/12 patients) and (8/4 patients), respectively]. There was a significant increase in the severe and critical patents in blood group A than in blood group $\mathrm{O}(15 / 5,30 / 3$, respectively). Mechanically ventilated and dead patients have a significant increase in blood group A than in blood group $\mathrm{O}(24 / 2,16 / 1$, respectively).

\section{Discussion}

The novel coronavirus disease (COVID-19, caused by the SARS-CoV-2 virus) has spread rapidly across the globe and has caused over 1,130,000 confirmed infections and over 62,000 deaths worldwide as of 5 April 2020 [6]. A number of risk factors for COVID-19 infection morbidity and mortality are known, including age, sex, and a number of chronic conditions and laboratory findings [1].

Biological factors that determine susceptibility to SARS-CoV-2 and severity of COVID-19 are yet to be fully understood. The ABO blood grouping may influence the susceptibility of COVID-19 and severity of the disease [7]. In this study, we found that $A B O$ blood groups have different association risks for the infection with SARS-CoV-2 resulting in COVID-19. Specifically, blood group A was associated with an increased risk than blood group $\mathrm{O}$. These findings are consistent with similar risk patterns of $\mathrm{ABO}$ blood groups for other coronavirus infections found in previous studies. For example, Cheng et al. reported that the SARS-CoV infection susceptibility in Hong Kong was differentiated by the ABO blood group systems [4]. The authors found that compared with non-O blood group hospital staff, blood group $\mathrm{O}$ hospital staff had a lower chance of getting infected. Many studies try to explain, and one study concluded that people with blood group $\mathrm{O}$ are able to recognize certain proteins as foreign and that may extend to proteins on virus surfaces so less likely to get a disease [8]. Another one found that anti-A antibodies inhibit binds of glycosylated SARS-COV S protein-expressing cells to angiotensin-converting enzyme 2 (ACE2) on cell surface, so these antibodies may block the interaction between the virus and its receptors thereby providing protection [9].

The activity of ACE2 in blood group B is much higher than in blood group $O$ [10] which leads to catching the virus too much that may explain why critical patient and mortality was higher in blood group $\mathrm{B}$ than blood group $\mathrm{O}$.

There was a link between blood group A and increase susceptibility of thromboembolism, diabetes mellitus, hypertension, recurrent urinary tract infections from $E$. coli, and $H$. pylori that can cause ulcers, stomach cancer, and heart diseases [11] so that another cause to explain why high mortality of COVID-19 in blood group A. Lastly there may be other mechanisms underlying why COVID-19 kills some people and spares others. HLAs represent just one in our immune system machinery, though, so their relative influence over COVID-19 infection remains unclear [12], noted that specific combinations of human leukocyte antigen (HLA) genes, which train immune cells to recognize germs, may be protective against SARS-CoV-2, while other combinations leave the body open to attack. Their analysis identified six HLA types with a high capacity to bind different SARS-CoV-2 protein sequences and three with a low capacity to do so. Specifically, a HLA type known as HLA-B*46:01 had the lowest predicted capacity to bind to bits of SARS-CoV-2 and associated with severe cases of infection. This speculation will need direct studies to prove it.

We believe that further longitudinal multi-center studies are highly needed to evaluate the clinical impact of those $\mathrm{ABO}$ groups in a single or multivariate analysis as a prognostic factor in COVID-19 patients.

\section{Conclusion}

In this study, there was an association between the $\mathrm{ABO}$ blood group and COVID-19 susceptibility and severity. Specifically, people with blood group A have a higher susceptibility and severity whereas people with blood group $\mathrm{O}$ have a lower one.

People with blood group A:

1) Might need strengthened personal protection to reduce the chance of infection. And if infection was caught, might need to close observation and aggressive treatment.

2) It might be helpful to introduce $A B O$ blood typing in the management of COVID-19 infection.

\section{Abbreviations}

ACEP: American College of Emergency Physicians; ACE2: Angiotensinconverting enzyme 2; BMI: Body mass index; DM: Diabetes mellitus; HLA: Human leucocytic antigen; HTN: Hypertension; WHO: World Health Organization

\section{Acknowledgements \\ All staff of chest diseases for the great help.}

Authors' contributions

HM was responsible for data collection and writing of the manuscript. SS was responsible for the interpretation of data and writing of the discussion. NR was responsible for the idea of the manuscript and review. All authors have read and approved the manuscript and ensure that this is the case.

\section{Funding}

WHO, up to date, Google search

Availability of data and materials

All data of the patient is available on a computerized patient file in the Recording Department of King Fahd Hospital-Almadina Almonoura, KSA. www.KFHM-moh.gov.sa. 


\section{Ethics approval and consent to participate}

King Fahd Hospital-Medina, KSA. Number (138) at 07/2020.

\section{Consent for publication}

The written consent from the patients was taken and is available when needed.

\section{Competing interests}

Not present in this section.

\section{Author details}

${ }^{1}$ Zagazig University, Zagazig, Egypt. ${ }^{2} \mathrm{KFH}-$ Almadina Almonoura, Riyadh, Kingdom of Saudi Arabia.

Received: 6 October 2020 Accepted: 27 December 2020

Published online: 03 February 2021

\section{References}

1. Zhou F, Yu T, Du R, Fan G, Liu Y, Liu Z, Xiang J, Wang Y, Song B, Gu X et al (2020) Clinical course and risk factors for mortality of adult inpatients with COVID-19 in Wuhan, China: a retrospective cohort study. Lancet. https://doi. org/10.1016/s0140-6736(20)30566-3

2. Dentali F, Sironi AP, Ageno W, Turato S, Bonfanti C, Frattini F et al (2012) Non-O blood type is the commonest genetic risk factor for VTE: results from a meta-analysis of the literature. Semin Thromb Hemost 38:535-548

3. Sun W, Wen CP, Lin J, Wen C, Pu X, Huang M et al (2015) ABO blood types and cancer risk-a cohort study of 339,432 subjects in Taiwan. Cancer Epidemiol 39:150-156

4. Cheng Y, Cheng G, Chui CH, Lau FY, Chan PK, Ng MH, Sung JJ, Wong RS (2005) ABO blood group and susceptibility to severe acute respiratory syndrome. JAMA 293(12):1450-1451

5. American College of Emergency Physicians (ACEP) (2020): COVID19 severity classification.

6. World Health Organization (WHO) (2020): Coronavirus disease 2019 situation reports. (2020-04-05) https://www.who.int/docs/default-source/coronaviruse/ situation-reports/20200405-sitrep-76-covid-19.pdf?sfvrsn=6ecf0977_2

7. Zhao J, Yang Y, Huang $\mathrm{H}$ et al (2020) Relationship between the ABO blood group and the COVID-19 susceptibility. https://doi.org/10.1101/2020.03.11. 20031096.8

8. Hari (2020) Blood type and COVID-19 risk: O may help, A may hurt. N Engl J Med 11:325-329

9. Laguipo ABB (2020) Blood types and COVID-19 risk confirmed. N Engl J Med

10. Chung CM, Wang RY, Chen JW et al (2020) A genome-wide association study identifies new loci for ACE activity: potential implications for response to ACE inhibitor. Pharmacogenomics J 10:537-544

11. Zhou S, Welsby I (2014) Is ABO blood group truly a risk factor for thrombosis and adverse outcomes. World J Cardiol 6(9):985

12. Austin N, David JK, Maden SK, Wood MA, Weeder BR, Nellore A, Thompsona RF (2020) Human leukocyte antigen susceptibility map for severe acute respiratory syndrome coronavirus 2. J Virol 94(13):e00510-e00520

\section{Publisher's Note}

Springer Nature remains neutral with regard to jurisdictional claims in published maps and institutional affiliations.

\section{Submit your manuscript to a SpringerOpen ${ }^{\circ}$ journal and benefit from:}

- Convenient online submission

- Rigorous peer review

- Open access: articles freely available online

- High visibility within the field

- Retaining the copyright to your article

Submit your next manuscript at $\boldsymbol{\nabla}$ springeropen.com 